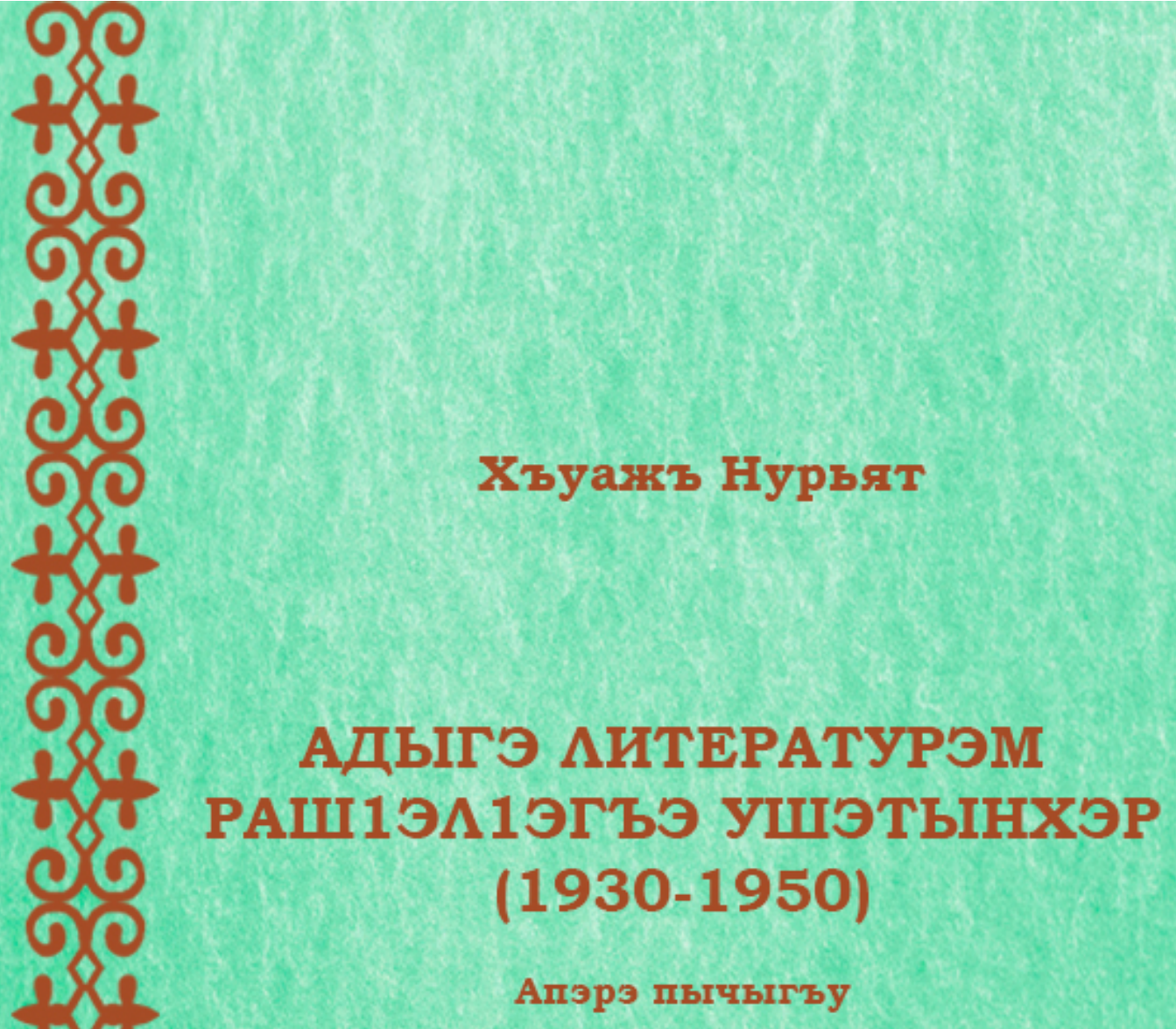

Егъэджэн Іэпыэгъу 
Адыгейский государственный университет Факультет адыгейской филологии и культуры

Кафедра адыгейской филологии

\section{Хужева Нурьят}

\section{АДЫГЕЙСКАЯ ЛИТЕРАТУРА \\ (1930-1950) \\ ХРЕСТОМАТИЯ ИССЛЕДОВАНИЙ}

часть первая

учебное пособие

Майкоп

ЭлИТ

2016 
УДК 82.0 (470.621) (075.8)

ББК 83.3 (2=Ады) я 73

X 98

\section{Публикуется по решению редакционно-издательского совета Адыгейского государственного университета.}

А в т ор - с о с та в и т е л : $\quad$ кандидат филологических наук

Хуажева Н. X.

Рецензенты :

доктор филологических наук, профессор

Унарокова Р. Б.,

доктор филологических наук,

профессор

Мамий Р. Г.

\section{Хуажева, Нурьят Хазретовна.}

Адыгейская литература (1930-1950). Хрестоматия исследований. Часть I. [Электронный ресурс]: электронное учебное пособие / Н.Х. Хуажева. - Майкоп: ЭлИТ, 2016. - 1 электрон. опт. диск (CD-R).

Хрестоматия исследований предназначена для изучения курса «История адыгейской литературы»».

В сборник вошли извлечения из малоизвестных работ адьгских филологов, исследовавиих адьгейскую литературу 1930-1950-х г2.

Книга может быть полезна для студентов и преподавателей средней и высшей иколь, а такюе для всех интересуюшихся историей и теорией адыгейской литературы.

Первое издание в печатном виде вынло в 2005 году (Майкоп: АГУ). 


\section{Оглавление}

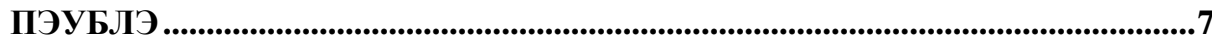

ТЕУЦОЖЬ ЦЫГЬО (1855-1940) ЫУСЫГЪЭМЭ АФЭГЬЭХЫЫГЪЭ

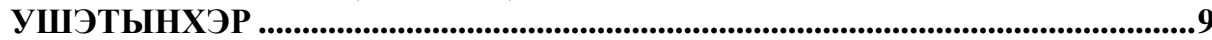

А. К. Тхакушинов К вопросу об идейно-художественном своеобразии жанра поэмы в адыгейской литературе (стр. 60-83) ........................................................

ХьэдэгъэлІэ А. Теуцожь Цыгъу. Историческэ поэмэхэр (н. 106-122)...............12

Шъхьэлэхъо А. ТЕУЦОЖЬ ЦЫГЪУ. Поэтическэ талантыр. Жэры1о

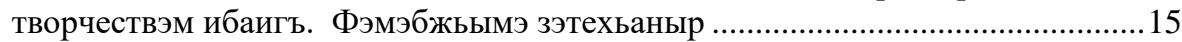

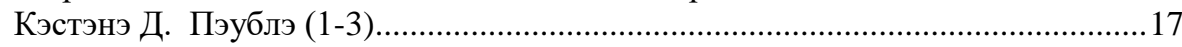

ХЬАМХЪУКЪО ХЪУСЕНЭ (1881-1934) ЫТХЫГЪЭМЭ АФЭГЪЭХЫЫГЪЭ

УШЭТЫНХЭР ............................................................................................21

Унарокова Р. Б. Кяхское культурно-просветительское движение начала века

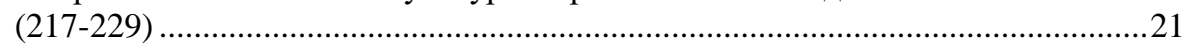

Унэрэкъо Р. Пэублэ (н. 7-36) «... Гопэ дэгъэкІэу нэжъым къыхехы»..............22

К1УБЭ ЩЭБАНЭ (1890-1974) ЫТХЫГЬЭМЭ АФЭГЪЭХЬЫГЬЭ

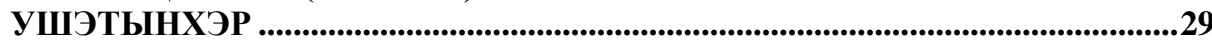

Щэш1э К. Къэзыгъэзэжьыгъэ мэкъамэхэр (н. 5-60)...........................................22

Шъхьэлэхъо А. Гъогупэхэр, къэгъэзап1эхэр, ик1ып1э къинхэр (н. 3-19) ........34

Ш. Е. Шаззо Глава четвертая (203-248) ................................................................ 34

ЛЬЭУСТЭН ЮСЫФ (1913-1998) ЫТХЫГЬЭМЭ АФЭГЬЭХЬЫГЬЭ

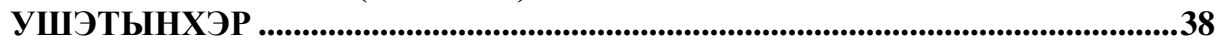

Цуамыкъо Т. Ц1ыфыкІэм икъэгъэлъэгъонкІэ амалыкІэхэр (6-37) .....................38

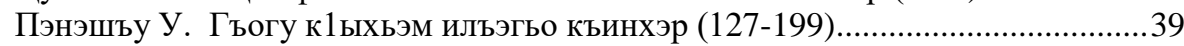

Шъхьэлэхъо А. Лъэгап1м ек1урэ гъогу (3-73) ..................................................40

Щэш1э К.Адыгэ романыр тыгьуасэрэ непэрэ (4-49) ............................................40

Мамый Р. Къуаджэр романым игупч (2-72) ...........................................................42

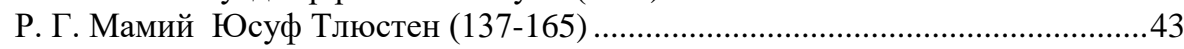

Р. Г. Мамий Реальность и художественная правда. Документальная основа и положительный идеал в прозе Ю. Тлюстена (стр. 269-309) ..............................44

Н. А. Приймакова Сюжет как важнейший элемент поэтики адыгского «традиционного» исторического романа (21-60) ...............................................46

ЕУТЫХ АСКЭР (1915-1999) ЫТХЫГЬЭМЭ АФЭГЬЭХЫЫГЬЭ

УШЭТЫНХЭР

А. К. Тхакушинов К вопросу об идейно-художественном своеобразии жанра поэмы в адыгейской литературе (стр. 60-83) ………........................................52

Г. Ш. Куваева Характеры и обстоятельства (Роман А. Евтыха «Улица во всю ее длину») (стр. 110-123) ……………………......................................................54

Г. Ш. Куваева Новый человек в адыгейском рассказе ........................................5

К. Шаззо. Новые рубежи (стр. 3-25) ……………………………………..............59 
К. Г. Шаззо Художественный конфликт, характеры и жанры развитого эпоса

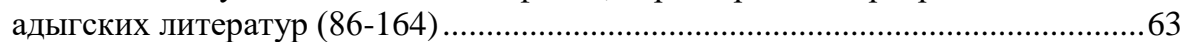
Щэш1э К. Тарихъым ишъолъыр зэфэшъхьафхэр (23-124)...............................65 Р. Г. Мамий Вопросы изучения современного адыгейского романа (стр. 1943).

Р. Г. Мамий Выбор пути. Аскер Евтых и идейно-эстетическая эволюция адыгейской литературы второй половины XX века (стр. 129-226)...................68

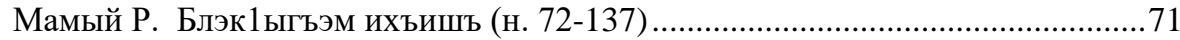

Ю. М. Тхагазитов Жанровые особенности романа $(81-103)$................................ 72

Ю. М. Тхагазитов Роль и функции мифоэпических традиций в адыгском

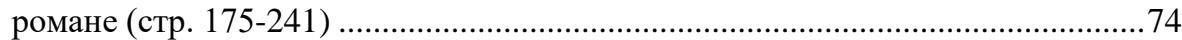

Къуныжъ М. Тхак1ом къыгъэзэжьыгъ (3-10) ..................................................75

Ф. Н. Хуако Художественное своеобразие лирической прозы Аскера Евтыха и его влияние на повесть 60-80-х годов (стр. 18-43) ...........................................78

$Ф$ Н. Хуако Художественное своеобразие прозы Аскера Евтыха и его влияние на повесть 60-80-х годов (22-54)...

Н. Х. Хуажева Гуманистическая концепция человека в дилогии А. Евтыха «Улица во всю ее длину» и «Двери открыты настежь» (стр. 125-126) .............84 Хъуажъ Н. Еутых А. и «Сшынахьыжъ» ехьыл1эгъэ гупшысэхэр (103-112)..85 Н. Хуажева О творческой концепции действительности в прозе Аскера

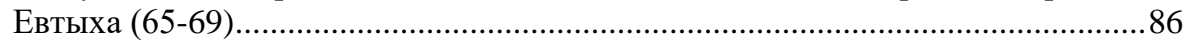

Хъуажъ Н. Гъогу къиным ыпсыхьэгъэ тхак1у (156-159) ...................................88

Б. 3. Чуякова Эволюция художественного конфликта в творчестве Аскера

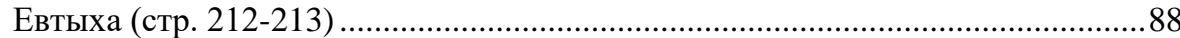

Д. А. Мерзаканова К творчеству Аскера Евтыха (Стр. 119-120).......................89 АНДЫРХЬОЕ ХЬУСЕНЭ (1920-1941) ЫТХЫГЬЭМЭ АФЭГЬЭХЬЫГЪЭ

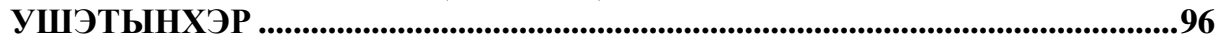

К.М.Шиков. Поэзия мужества (стр. 43-63) ….............................................96

Х. И. Баков Творческая индивидуальность и эволюция лирики в адыгской

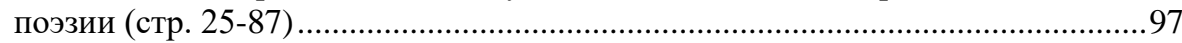

Пэнэшъу У. Гъогу к1ыхьэм ильэгъо къинхэр (127-199) ....................................98

А. А. Схаляхо Андрухаев Хусен. Зов времени. Сила и жизнь поэтического

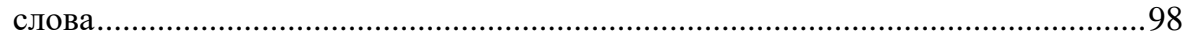

Шъхьэлэхъо А. 1ашэм дык1ыгъоу ягущы1и агъэчанзэ (74-98).........................99 Шъхьэлэхъо А. Андырхъое Хъусен. Уахътэм иджэмакъ. Поэтическэ псалъэм

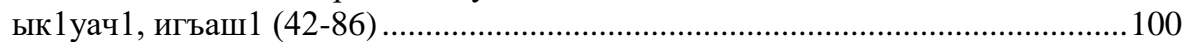
К. Н. Паранук Хусен Андрухаев (112-120) .........................................................103 КЭСТЭНЭ ДМИТРИЙ (1912-1985) ЫТХЫГЬЭМЭ АФЭГЬЭХЫЫГЪЭ

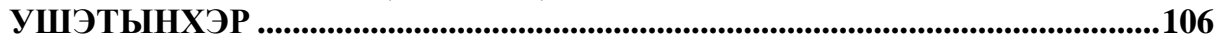

Л. Г. Голубева Дмитрий Костанов (Роман «Слияние рек») (стр. 70-88).......106 А. А. Гадагатль Система образов в романе Д. Костанова «Белая кувшинка»

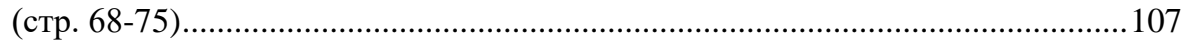


ХьэдэгъалІэ А.Адыгэ литературам ироманык1эхэр (Д. Кэстанэмрэ И.

МэщбашІэмрэ яроманыкІэхэм яхьыл 1агъ) (н. 30-48)

Щэш1э К. Романыр ык1и лъэхъаныр (Д. Кэстан «Шэуджэн Мос») (78-105)113

Л. Г. Мамий Изображение положительного героя в прозе первого

послевоенного десятилетия (стр. 69-84)

Р. Г. Мамий Современный адыгейский роман о революционном прошлом

(стр. 146-188)

Мамый Р.Къуаджэр романым игупч (2-72)................................................122

Цуамыкъо Т. Ц1ыфык1эм икъэгъэлъэгъонк1э амалык1эхэр (6-37) .................123

Шъхьэлэхъо А. Шэуджэн Мосэ иобраз фольклорымрэ литературэмрэ

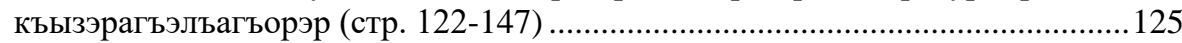

Шъхьэлэхъо А. Ц1ыфхэм янасып пае (157-182) ................................................130

Шъхьэлэхъо А. 1ашэм дык1ыгъоу ягущы1 и агъэчанзэ (74-99) .........................131

А. А. Схаляхо Основные тенденции развития адыгейской советской

литературы 60-80 гг. Художественные поиски и открытия (189-228) ............132

Шъхьэлэхъо А. Кэстэнэ Дмитрий. Щы1эныгъэ шъыпкъагъэр ишапхъэу.

Образым и1упк1агъ. Пейзажыр, ащ ихудожественнэ к1оч1эдэк 1 (310-331) 132

Шъхьэлэхъо А. 1ушыгъэр ишапхъэу (466-475)..............................................133

ЯХЬУЛ1Э СЭФЭР (1914-1977) ЫТХЫГЪЭМЭ АФЭГЬЭХЫЫГЬЭ

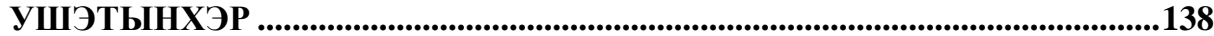

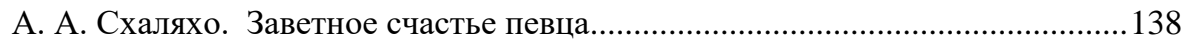

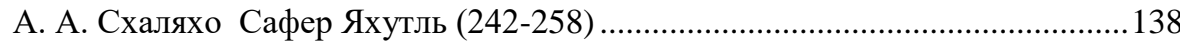

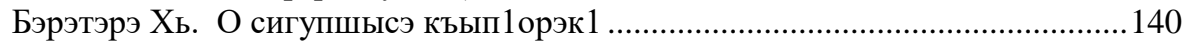

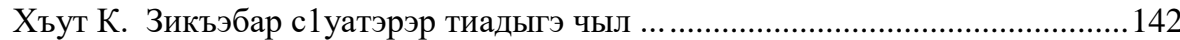

Хъут К. Адыгэ поэзием изынэк1убгъу (3-12) .................................................143

ЖЭНЭ КЫЫРЫМЫЗЭ (1919-1983) ЫТХЫГЬЭМЭ АФЭГЬЭХЫЫГЪЭ

УШЭТЫНХЭР ................................................................................................................145

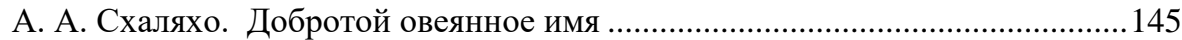

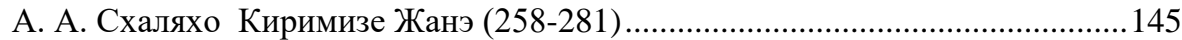

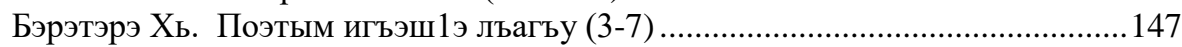

Хъут К. Ц1ык1ухэми инхэми афэусагъ (5-11) ................................................148

Х. Г. Тлепцерше Во имя любви людской (138-139)......................................150

Боджэкъо Б. Пшъэшъэжъыем ип1ун Жэнэ Къырымызэ мэхьанэу ритрэр

ик 1 элэц 1 ык 1 у усэхэм къызэрахэщрэр.................................................................151

Н. С. Васильева Художественное своеобразие рассказов К. Жанэ (100-107) 


\title{
Учебное пособие
}

\author{
Хуажева Нурьят Хазретовна
}

\section{АДЫГЕЙСКАЯ ЛИТЕРАТУРА \\ (1930-1950) \\ ХРЕСТОМАТИЯ ИССЛЕДОВАНИЙ \\ Часть I}

Подписано к публикации 30.03.2016 г.Усл. печ. л. 8,5

Общество с ограниченной ответственностью

"Электронные издательские технологии"

385020, Российская Федерация, Республика Адыгея, a/я 09

E-mail: elit-publishing@ya.ru.

Тел.: 8(928)4-719-729. 